\title{
Prevalence of feet and ankle arthritis and their impact on clinical indices in patients with rheumatoid arthritis: a cross-sectional study
}

Sung Won Lee ${ }^{1,2}$, Seong-Yong Kim ${ }^{3}$ and Sung Hae Chang ${ }^{1,2^{*}}$

\begin{abstract}
Background: We aimed to evaluate the prevalence of foot and/or ankle arthritis (FAA) and its impact on clinical indices in patients with rheumatoid arthritis (RA).

Methods: This cross-sectional study used data from the Korean College of Rheumatology Biologics \& Targeted therapy registry to observe clinical outcomes of patients undergoing biologics therapy and conventional therapy. FAA was defined as $\geq 1$ tender or swollen joint in the ankle and/or 1st-5th metatarsophalangeal (MTP) joints. Disease Activity Score 28 (DAS28), Routine Assessment of Patient Index Data 3 (RAPID3), Simplified Disease Activity Index (SDAI), and Clinical Disease Activity Index (CDAl) were assessed.

Results: Among 2046 patients, 598 had FAA. The ankle joint was the most commonly involved joint in FAA (tender joint, 71.4\%; swollen joint, 59.5\%), followed by the third and second MTP joints. Patients with FAA showed higher DAS28, RAPID3, SDAl, and CDAI scores. FAA presence was significantly associated with non-remission as per DAS28ESR (odds ratio, 3.4; 95\% confidence interval, 2.0-5.8), DAS28-CRP (3.6, 2.4-5.3), SDAI (6.3, 2.8-14.6), CDAI (7.6, 2.424.3), and RAPID3 (5.6, 2.7-11.5) indices on adjusting for age, sex, disease duration, presence of rheumatoid factor, presence of anti-cyclic citrullinated peptide antibody, lung disease, use of methotrexate, and previous use of biological disease-modifying anti-rheumatic drugs. Patients with FAA were less likely to achieve remission of SDAI $(n=6,1.0 \%)$ and CDAI $(n=3,0.5 \%)$ than that of DAS28-ESR $(n=21,3.5 \%)$, DAS28-CRP $(n=38,6.4 \%)$, and RAPID3 $(n=12,2.0 \%)$.
\end{abstract}

Conclusions: FAA represents a severe disease activity and is an independent risk factor for non-remission in patients with RA.

Keywords: Rheumatoid arthritis, Foot, Ankle, Disease activity index, Biologics therapy, Metatarsophalangeal joints

\section{Background}

Rheumatoid arthritis (RA) is a systemic inflammatory disease that can involve the synovial joint. Foot and ankle are commonly affected, and more than $90 \%$ of patients with RA reported foot pain during the course of

\footnotetext{
* Correspondence: imdrrheum@sch.ac.kr

'Division of Rheumatology, Department of Internal Medicine, Soonchunhyang University Cheonan Hospital, Cheonan, Korea

'Division of Rheumatology, Department of Internal Medicine,

Soonchunhyang University College of Medicine, Cheonan,

Chungchungnam-do, Korea

Full list of author information is available at the end of the article
}

their disease [1]. Even in patients with early RA, $70 \%$ of patients had foot synovitis less than 3 years since the onset of symptoms. Radiographic damage to the feet was observed in about one-fifth of the patients, and the proportion increased to $60 \%$ after 8 years [2]. Foot arthritis results in impaired foot function, which is associated with frequent falls [3].

RA can be assessed using various parameters; the disease activity indexes are comprised of multiple factors, including patient's global assessment (PGA), evaluator's global assessment (EGA), C-reactive protein (CRP), or erythrocyte sedimentation rate (ESR) to measure joint 
inflammation and disease activity. The most extensively validated and widely used index is the Disease Activity Score (DAS). However, the formula for DAS using 28 joint counts is complicated [DAS28 $=(0.56$ * tender joint count $1 / 2)+(0.28 *$ swollen joint count $1 / 2)+(0.7 * \ln$ $[\mathrm{ESR}])+(0.014 * \mathrm{VAS})][4,5]$. Therefore, simplified disease activity index (SDAI) or clinical disease activity index (CDAI) was developed, which offers simpler calculation with the arithmetic sum of swollen joint counts (SJS), tender joint counts (TJC), PGA, EGA, CRP for SDAI and SJS, TJC, PGA, EGA for CDAI for CDAI [4, 6]. All three indices are correlated [4, 7]. However, the disease activity index excludes foot and ankle joints, and there have been controversies whether these composite indices represent the actual disease activity involving foot and ankle joints [8-11]. Wechalekar et al. reported that $43 \%$ of patients with a DAS28-ESR of $<2.6$ had foot synovitis, and 25$36 \%$ of patients with remission as per SDAI and CDAI had foot synovitis [8].

In the current study, we investigated the prevalence of FAA, an association of FAA with disease activity indices, and the impact of FAA on disease activity. Although there are several studies on the prevalence or disease activity in patients with FAA, the current study is the one with the most significant number of patients.

\section{Methods}

The Korean College of Rheumatology Biologics \& Targeted therapy (KOBIO) registry, a multicenter hospital-based observational registry designed by the Korean College of Rheumatology (KCR), was established in 2012 to assess clinical courses, outcomes, and adverse events in patients on biologic disease-modifying anti-rheumatic drug (bDMARD) therapy that was explained in a previous study [12]. Patients with RA were recruited from 38 hospitals in South Korea. Briefly, all patients satisfied the 2010 ACR/EULAR RA classification criteria or 1987 ACR RA classification criteria. Baseline demographic data were collected including age, gender, body mass index (BMI), and smoking status at the time of enrolment and annually thereafter. Laboratory data, including rheumatoid factor (RF), anticyclic citrullinated peptide (anti-CCP) antibody, CRP, and ESR, and current medications, including the use of glucocorticoids disease-modifying anti-rheumatic drugs (DMARDs) such as methotrexate (MTX) and bDMARDs, were investigated by review of medical records. The treating physician performed 44 SJCs, 44 TJCs, and EGA. The treating physicians counted the swollen or tender joints only considered to be associated with RA. Radiographic damage, i.e., presence of joint space narrowing or bone erosion was surveyed by either the treating rheumatologist or a radiologist. PGA and Routine Assessment of Patient Index Data 3
(RAPID3) were also evaluated. DAS28-ESR, DAS28CRP, SDAI, and CDAI were also assessed. Remission status was also evaluated using the 2011 ACR/EULAR Boolean-based remission criteria [13]. All items were assessed at enrolment and at annual follow-up visits; however, in the current study, we used only the baseline data. Written informed consent was obtained from all participants. The study was approved by the ethics committee or institutional review boards of each centre and was conducted in accordance with the Helsinki Declaration of 1975 as revised in 2008. All patient data were transferred by individual investigators to the KOBIO web server (http://www.rheum. or.kr/kobio/). In the current study, FAA was defined as one or more tender or swollen joints in the ankle and/or the first to fifth metatarsophalangeal (MTP) joints.

\section{Statistical analysis}

Data are presented as mean \pm standard deviation or percentage for patients with FAA or those without FAA, as appropriate. Means were analysed using the Student's $t$ test for parametric variables, and the Mann-Whitney test for the non-parametric variables according to the normality of the variables. Categorical variables were compared using the chi-square or Fisher's exact test. $P$ values $\leq 0.05$ were considered significant. Logistic multivariate regression analysis was performed to clarify if FAA was statistically significant as an independent risk factor for non-remission. Factors known to be associated with remissions, such as age, sex, duration of disease, presence of RF, presence of anti-CCP, existence of lung disease, use of MTX, and previous use of bDMARDs were included for multivariate analysis. TJC, SJC, EGA, PGA, ESR, and CRP were not included in the multivariate analysis because they were included in the dependent factors (i.e. disease activity indices). All analyses were performed using the PASW Statistics 18 (SPSS Inc., Chicago, IL, USA).

\section{Results \\ Prevalence of FAA and clinical characteristics of patients with FAA}

Of 2046 patients registered by March 2017, 598 (29.2\%) had FAA. The age at enrolment was comparable between patients with FAA and those without FAA. Females had higher incidence rate of FAA $[30.1 \%(n=520$ of 1729$)$ in females vs $24.6 \%$ ( $n=78$ of 317$)$ in males, $p=0.05]$. Patients with FAA had a longer duration of the disease than those without. The BMI was similar between the two groups. Current or ex-smoker to nonsmoker rate was comparable between the two groups. No significant difference was noted between groups with regard to anti-CCP antibody positivity rate. There were 
no significant intergroup differences in terms of steroid use, but the doses were significantly different between groups $(5.2 \pm 10.7 \mathrm{mg} /$ day for patients with FAA vs $4.3 \pm$ $4.2 \mathrm{mg} /$ day for those without FAA; $p=0.003$ ). The proportion of patients with previous use of bDMARDs was higher in the FAA group than that in the non-FAA group (Table 1).

\section{Distribution of FAA}

Among patients with FAA, ankle was the most common tender $(n=427 / 598,71.4 \%)$ or swollen $(n=356 /$ 598, 59.5\%) joint. Of MTP joints, the third MTP joint $(n=185 / 598,30.9 \%)$ was the most common tender joint, followed by the second $(n=177,29.6 \%)$, fourth $(n=165,27.6 \%)$, first $(n=157,26.3 \%)$, and fifth $(n=$ $113,18.9 \%)$ MTP joints. The third MTP joint $(n=$ $134 / 598,22.4 \%)$ was the most common swollen joint, followed by the second $(n=128,21.4 \%)$, fourth $(n=$ $110,18.4 \%)$, first $(n=89,14.9 \%)$, and fifth $(n=63$, 10.5\%) MTP joints.

\section{High disease activity and increased radiographic damage in patients with FAA}

The 44 SJCs, 44 TJCs, PGA, and EGA showed higher scores in patients with FAA than in those without FAA (Table 1). Of the total number of patients, the remission rate was $8.6 \%(n=174), 17.0 \%(n=343), 5.9 \%(n=120)$, $3.5 \%(n=72), 6.9 \%(n=140)$, and $4.3 \%(n=87)$ as per DAS28-ESR, DAS28-CRP, SDAI, CDAI, RAPID3 and Boolean-based definition of remission, respectively. Patients with FAA had higher PGA, EGA, DAS28, SDAI, CDAI, and RAPID3 scores (Table 1). Patients with FAA were less likely to achieve remission in SDAI $(n=6$, $1.0 \%)$ and CDAI $(n=3,0.5 \%)$ than in DAS28-ESR $(n=21,3.5 \%)$, DAS28-CRP $(n=38,6.4 \%)$, RAPID3 $(n=12,2.0 \%)$ (Fig. 1). Five patients $(0.8 \%)$ with FAA achieved remission as per the Boolean-based definition of remission.

The radiographic results were available for a total of 1737 hands and $1297 \mathrm{ft}$. Patients with FAA showed more bone erosion not only on radiographs of the foot [total $n=1265,36.7 \%(n=153)$ for patients with FAA vs $29.1 \%(n=247)$ for those without FAA, $p=$ 0.007] but also on radiographs of the hand [total $n=$ $1693,40.0 \%(n=197)$ for patients with FAA vs $34.8 \%$ $(n=417)$ for those without FAA, $p=0.05$ ] (Table 1).

On multivariate analysis for index-based remission, the presence of FAA was significantly associated with a reduced likelihood of remission in DAS28 ESR, DAS28-CRP, SDAI, CDAI, and RAPID3 after adjusting for age, duration of disease, presence of RF, presence of anti-CCP, existence of lung disease, use of MTX, and previous use of bDMARDs (Table 2).

\section{Near misses by Boolean-based definition of remission} caused by PGA, which was not affected by FAA

In this study, $38.2 \%(n=766), 31.1 \%(n=623), 12.5 \%$ $(n=250), 13.9 \%(n=279)$, and $4.3 \%(n=87)$ of the patients satisfied $0,1,2,3$, and 4 items of the four items included in the Boolean-based definition of remission, respectively. The most common reason for the near misses of Boolean-based definition of remission (i.e., patients satisfying only 3 items) was the PGA score $>1$ $(n=261,93.5 \%)$, followed by CRP level of $>1 \mathrm{mg} / \mathrm{dL}$ $(n=7,2.5 \%), \mathrm{SJC}>1$ of SJC $(n=7,2.5 \%)$, and TJC $>1$ of TJC $(n=4,1.4 \%)$. Among patients with near misses of Boolean-based definition of remission due to PGA, only $14.2 \%(n=37)$ patients had FAA.

\section{Discussion}

KOBIO registry was established to investigate the effects and adverse events of bDMARDs. In Korea, since July 2009, the government has provided expanded benefit coverage in the national health insurance for patients with rare incurable diseases (the Exempted Calculation of Health Insurance for rare, incurable diseases). However, only seropositive RA patients (positive either for $\mathrm{RF}$ or anti-CCP antibody) have this advantage. Therefore, presence of RF and anti-CCP antibody was high in this cohort. Moreover, because most of the enrolled patients were considered to initiate or change bDMARD treatment, the proportion of patients with RA-associated lung diseases was low.

In the current study, the prevalence of FAA $(29.2 \%)$ was far less than that reported in a previous study, in which $70 \%$ of the patients among the cohort with early RA with a symptom duration of $<3$ years had at least one or more MTP joint pain and swelling [14]. However, in that study, these cases were classified as RA according to the 1987 ACR criteria known to detect relatively advanced RA, while most patients in the current study were diagnosed as RA using the 2010 ACR classification criteria, which is known to detect early RA. Accordingly, patients with RA diagnosed based on 1987 ACR criteria may showhave radiographic damages, even those with < 3 years since the onset of symptoms.

There are several factors for FAA other than RA, including high BMI, occupation, or other concurrent medical conditions, such as gout or osteoarthritis (OA). These factors might affect the result of the present study, but their effect may be not influential enough to mask the burden of RA on FAA. Although increased BMI is associated with arthritis in the lower extremities $[15,16]$, the BMI between patients with and without FAA in the current cohort was not statistically different, and the mean of the BMI was $22.6 \pm 3.3 \mathrm{~kg} / \mathrm{m}^{2}$, which is far less than that among patients in those studies (32.1 \pm $8.4 \mathrm{~kg} / \mathrm{m}^{2}$ ) [16]. The coexistence of gout and RA has 
Table 1 Demographic and clinical data of patients with and without foot and/or ankle arthritis

\begin{tabular}{|c|c|c|c|}
\hline & With FAA & Without FAA & $P$-values \\
\hline & $(598,29.2 \%)$ & $(1448,70.8 \%)$ & \\
\hline \multicolumn{4}{|l|}{ Demographic Characteristics } \\
\hline Female, $n(\%)$ & $520(87.0)$ & $1209(83.5)$ & 0.05 \\
\hline Age at the time of enrollment, years & $54.1 \pm 12.6$ & $54.4 \pm 13.0$ & 0.63 \\
\hline Disease duration, years & $8.5 \pm 8.3$ & $7.4 \pm 7.0$ & $<0.01$ \\
\hline Disease duration < 1 year, $n(\%)$ & 99 (16.6) & $228(15.8)$ & 0.69 \\
\hline Disease duration < 2 years, $n(\%)$ & $170(28.5)$ & $399(27.7)$ & 0.70 \\
\hline Disease duration < 3 years, $n(\%)$ & 200 (33.6) & $509(35.3)$ & 0.47 \\
\hline Disease duration < 4 years, $n$ (\%) & $241(40.4)$ & $622(43.1)$ & 0.28 \\
\hline Disease duration $<5$ years, $n(\%)$ & $273(45.8)$ & $71(49.6)$ & \\
\hline Disease duration $\geq 5$ years, $n(\%)$ & $323(54.2)$ & $727(50.4)$ & 0.12 \\
\hline Body mass index, $\mathrm{kg} / \mathrm{m}^{2}$ & $22.6 \pm 3.6$ & $22.6 \pm 3.2$ & 0.97 \\
\hline Current/ex-smoker, $n$ (\%) & $89(14.9)$ & $217(15.0)$ & 1.00 \\
\hline Presence of RA-associated lung diseases, $n$ (\%) & $21(3.5)$ & $47(3.3)$ & 0.79 \\
\hline Positive for rheumatoid factor, $n(\%)$ & $491(85.1)$ & $1174(83.5)$ & 0.38 \\
\hline Positive for anti-cyclic citrullinated peptide, $n(\%)$ & $404(84.7)$ & $1046(85.1)$ & 0.88 \\
\hline \multicolumn{4}{|l|}{ Radiographic damage } \\
\hline \multicolumn{4}{|l|}{ Hand X-ray } \\
\hline Erosion, $n(\%)$ & $197(40.0)$ & $417(34.8)$ & $<0.05$ \\
\hline Joint space narrowing, $n$ (\%) & $226(45.8)$ & $555(46.5)$ & 0.83 \\
\hline \multicolumn{4}{|l|}{ Feet X-ray } \\
\hline Erosion, $n(\%)$ & $153(36.7)$ & $247(29.1)$ & $<0.01$ \\
\hline Joint space narrowing, $n$ (\%) & $107(25.7)$ & $224(26.5)$ & 0.79 \\
\hline \multicolumn{4}{|l|}{ Medication } \\
\hline Current glucocorticoid use, $n(\%)$ & $497(83.1)$ & $1169(80.7)$ & 0.21 \\
\hline Daily dose (prednisolone equivalent), mg & $5.2 \pm 10.7$ & $4.3 \pm 4.2$ & $<0.01$ \\
\hline Current use of MTX, $n(\%)$ & $567(94.8)$ & $1337(92.3)$ & 0.05 \\
\hline Previous use of bDMARDs, $n$ (\%) & $145(24.2)$ & $233(16.1)$ & $<0.01$ \\
\hline \multicolumn{4}{|l|}{ Disease activity } \\
\hline Swollen joint count (44 joints examined) & $8.9 \pm 6.8$ & $3.9 \pm 4.4$ & $<0.01$ \\
\hline Tender joint count (44 joints examined) & $11.9 \pm 8.6$ & $4.9 \pm 5.0$ & $<0.01$ \\
\hline Patients Global Assessment score (1-10 mm) & $6.7 \pm 2.3$ & $5.7 \pm 2.6$ & $<0.01$ \\
\hline Evaluator's Global Assessment score (1-10 mm) & $6.0 \pm 5.2$ & $5.2 \pm 2.6$ & $<0.01$ \\
\hline $\mathrm{ESR}, \mathrm{mm} / \mathrm{h}$ & $48.8 \pm 29.2$ & $41.3 \pm 27.2$ & $<0.01$ \\
\hline $\mathrm{CRP}, \mathrm{mg} / \mathrm{dL}$ & $2.6 \pm 3.3$ & $1.7 \pm 2.3$ & $<0.01$ \\
\hline DAS28-ESR score & $5.6 \pm 1.4$ & $4.7 \pm 1.5$ & $<0.01$ \\
\hline DAS28-CRP score & $4.9 \pm 1.4$ & $4.0 \pm 1.5$ & $<0.01$ \\
\hline SDAl score & $30.3 \pm 14.3$ & $21.3 \pm 12.8$ & $<0.01$ \\
\hline CDAl score & $27.8 \pm 13.2$ & $19.7 \pm 11.9$ & $<0.01$ \\
\hline RAPID3 score & $15.9 \pm 6.0$ & $12.4 \pm 6.6$ & $<0.01$ \\
\hline \multicolumn{4}{|l|}{ The proportion of patients with remission } \\
\hline DAS28-ESR, n (\%) & $21(3.5)$ & $153(10.7)$ & $<0.01$ \\
\hline DAS28-CRP, $n(\%)$ & $38(6.4)$ & $305(21.4)$ & $<0.01$ \\
\hline $\mathrm{SDAl}, n(\%)$ & $8(1.3)$ & $112(7.7)$ & $<0.01$ \\
\hline
\end{tabular}


Table 1 Demographic and clinical data of patients with and without foot and/or ankle arthritis (Continued)

\begin{tabular}{llll}
\hline & With FAA & Without FAA & $(1448,70.8 \%)$ \\
\hline CDAl, $n(\%)$ & $(598,29.2 \%)$ & $69(4.8)$ & $<0.01$ \\
RAPID3, $n(\%)$ & $3(0.5)$ & $128(8.9)$ & $<0.01$ \\
Boolean-based criteria, $n(\%)$ & $12(2.0)$ & $82(5.8)$ & $<0.01$ \\
\hline
\end{tabular}

been rarely reported [17]. About $40 \%$ of patients with RA have concurrent foot OA [18], and the most commonly affected joint in foot OA is the first MTP joint, and $\mathrm{OA}$ is rarely associated with ankle joints; in the current study, the most commonly affected joints in FAA were ankle joints, followed by the third and second MTP joints. Further, the treating physician assessed the joints and considered them as swollen or tender joints only if they were considered to be associated with RA in the present study.

Presence of FAA denotes more aggressive and severe disease status. Predominant foot progressors showed more radiographic progression for the same changes in DAS28 than hand and foot progressors, predominantly hand progressors, or non-progressors $[19,20]$. In the current study, patients with FAA showed higher overall activity than those without FAA, and noticeable radiographic damage was more frequent not only in feet but also in hands (Table 1). Presence of FAA is a consistently significant factor for no remission in all disease activity index (Table 2). Notably, patients with FAA of longer duration are less likely to be in remission. (Additional file 1: Table S2).

There are still controversies regarding the 28 joint count-based indices, which represent entire joints, except foot and ankle joints. Although $29-30 \%$ of patients with DAS28 remission have foot arthritis, the remission rate and joint activity over time were comparable between the 28 -joint count-based indices and 32 -joint count-based indices $[10,21]$. The basis of representativeness of those indexes is that the presence of FAA may be implicated in subjective measures, such as PGA and EGA, albeit they do not include FAA in the 28-joint count. In the current study, among patients with DAS28 remission, PGA was significantly higher among patients with FAA than among those without FAA (Additional file 1: Table S1). Of note, PGA may be affected by other conditions, such as depression or fibromyalgia. Unsatisfied PGA is the limiting factor for Boolean-based

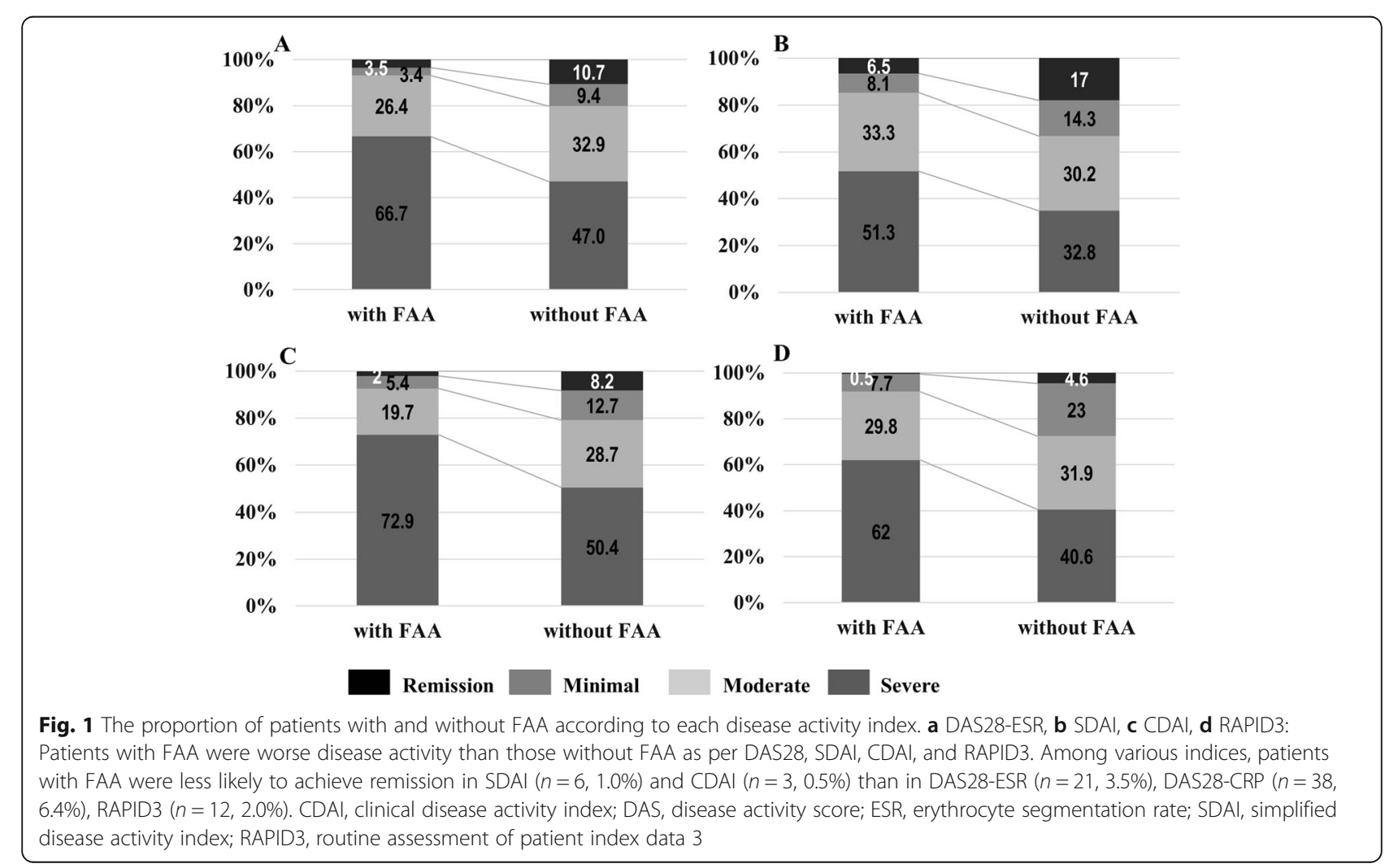


Table 2 Multivariate analysis ${ }^{\mathrm{a}}$ for no remission according to each clinical index

\begin{tabular}{|c|c|c|c|}
\hline & OR & $95 \% \mathrm{Cl}$ & $P$-value \\
\hline \multicolumn{4}{|l|}{ DAS28-ESR, no remission } \\
\hline Disease duration, years & 1.02 & $1.00-1.05$ & 0.10 \\
\hline Positive for rheumatoid factor & 2.18 & $1.47-3.22$ & $<0.00$ \\
\hline Previous use of bDMARDs & 4.37 & $2.00-9.54$ & $<0.00$ \\
\hline Presence of FAA & 3.43 & $2.01-5.84$ & $<0.00$ \\
\hline \multicolumn{4}{|l|}{ DAS28-CRP, no remission } \\
\hline Presence of lung disease & 3.53 & $1.08-11.53$ & 0.04 \\
\hline Positive for rheumatoid factor & 1.64 & $1.18-2.29$ & $<0.00$ \\
\hline Previous use of bDMARDs & 4.25 & $2.47-7.31$ & $<0.00$ \\
\hline Presence of FAA & 3.59 & $2.43-5.33$ & $<0.00$ \\
\hline \multicolumn{4}{|l|}{ SDAl, no remission } \\
\hline Previous use of bDMARDs & 6.77 & $2.13-21.5$ & $<0.00$ \\
\hline Presence of FAA & 6.33 & $2.75-14.6$ & $<0.00$ \\
\hline \multicolumn{4}{|l|}{ CDAl, no remission } \\
\hline Previous use of bDMARDs & 5.94 & $1.44-24.49$ & $<0.00$ \\
\hline Presence of FAA & 7.59 & $2.37-24.33$ & $<0.00$ \\
\hline \multicolumn{4}{|l|}{ RAPID, no remission } \\
\hline Use of MTX & 2.6 & $0.94-7.23$ & 0.07 \\
\hline Previous use of bDMARDs & 8.22 & $2.59-26.11$ & $<0.00$ \\
\hline Presence of FAA & 5.57 & $2.69-11.52$ & $<0.00$ \\
\hline
\end{tabular}

${ }^{a}$ Factors known to be associated with remission such as age, disease duration, the positivity of RF, positivity of anti-cyclic citrullinated peptide, the existence of lung disease, use of MTX, previous use of bDMARDs were included for multivariate logistic regression analysis

complete remission [20], and factors other than RA such as depression and fibromyalgia associated with failure to meet PGA $\leq 1$ [22]. In the current study, the most common reason for the near-miss of Boolean-based complete remission was also unsatisfied PGA, but only $14.2 \%$ of these patients had FAA. Therefore, although subjective components of 28-joint count-based index compensate for missed FAA, PGA alone is not enough and both PGA and EGA should be considered. Among patients with remission as per SDAI and CDAI, which involves EGA and is more weighted on PGA than DAS28, only $6.7 \%(8 / 120$, SDAI remission) and 4.2\% (3/72, CDAI remission) patients were diagnosed with FAA, whereas $12.1 \%$ (21/ $174)$ and $11.1 \%(38 / 343)$ patients with remission as per DAS28-ESR and DAS28-CRP had FAA, respectively, in the present study. Accordingly, among the 28-joint count-based index, SDAI and CDAI may be more applicable to reflect actual disease activity concerning FAA.

The current study has several limitations. First, assessments were conducted every year so we cannot be sure of the status during the 12 months. However, despite this limitation, this is one of the largest RA cohorts worldwide. Second, we defined FAA as the presence of swollen or tender joints in the first to fifth MTP or ankle joints, which may provoke controversy because arthritis included both swollen and tender joint in most studies. Prevalence of FAA was $19.8 \%(n=403)$ in the present study cohort if FAA includes both swollen and tender joints, which is far less than that in previous studies as discussed above. Because it is challenging to assess swollen joint count on occasion [23], and underestimation rather than overestimation is suspected in this large cohort, we considered to define FAA as one or more tender or swollen joints in the ankle and/or first to fifth metatarsophalangeal (MTP) joints. Further studies using ultrasound-detected synovitis may be needed, but this needs intense effort to evaluate more than 2000 patients as in the present study, and there may be issues in standardizing the ultrasound technique as it is may vary with the examiner.

\section{Conclusion}

In conclusion, approximately $30 \%$ of patients with RA have FAA. Presence of FAA represents a more severe disease activity status and is an independent risk factor for non-remission in patients with RA. Among clinical indices, SDAI and CDAI best represent FAA.

\section{Additional files}

Additional file 1: Table S1. Demographic and clinical data of patients with DAS28-ESR remission (total $n=174)$. (DOCX $25 \mathrm{~kb}$ )

Additional file 2: Supplementary file. (DOCX $14 \mathrm{~kb}$ )

\section{Abbreviations}

ACR/EULAR: American College of Rheumatology/European League Against Rheumatism; anti-CCP: anti-cyclic citrullinated peptide; bDMARDs: biologic disease-modifying anti-rheumatic drugs; BMI: Body mass index; CDAl: clinical disease activity index; CRP: C-reactive protein; DAS: Disease activity score; EGA: Evaluator's global assessment; ESR: Erythrocyte sedimentation rate; FAA: Feet and/or ankle arthritis; KOBIO: The Korean nationwide BIOlogics registry; MTP: Metatarsophalangeal; MTX: Methotrexate; OA: Osteoarthritis; PGA: Patient's global assessment; RA: Rheumatoid arthritis; RAPID3: Routine assessment of patient index data 3; RF: Rheumatoid factor; SDAI: Simplified disease activity index; SJCs: Swollen joint counts; TJCs: Tender joint counts

\section{Acknowledgments}

The authors are grateful for the collaboration of all rheumatologists and their nurses in Korea for providing the data and for the patients and their families for their participation.

\section{Authors' contributions}

All authors have read and approved the manuscript. SHC conceived and planned the study, interpreted the data, and wrote the draft of the manuscript. SWK contributed to data cleaning, analysis, and interpretation. SWL contributed to manuscript drafting.

\section{Funding}

The registry was funded by the Korean College of Rheumatology. The funding source was not involved in the study design, collection, analysis, and 
interpretation of the data; in writing the manuscript; and in the decision to submit the manuscript for publication.

The Soonchunhyang University Research Fund and the National Research Foundation of Korea (NRF) grant funded by the Korea government (MSIT) (No. 2018R1C1B5045586) supported this study for publication and language editing fees.

\section{Availability of data and materials}

The datasets used and/or analyzed during the current study are available from the corresponding author on reasonable request. Korean College of Rheumatology Biologics \&Targeted therapy Registry web site: http://www. kobio.or.kr/kobio/

\section{Ethics approval and consent to participate}

This study was approved by the ethics committee of all institutions involved including Institutional Review Board (IRB) of Soonchunhyang University Cheonan Hospital (IRB number: 2015-12-012). Informed consent was obtained by each involved institution. Informed written consent from patients was obtained by each involved institution. The full names of ethics committees of the participating institutions are provided by Additional file 2 .

\section{Consent for publication}

Not applicable

\section{Competing interests}

The authors declare that they have no competing interests.

\section{Author details}

'Division of Rheumatology, Department of Internal Medicine,

Soonchunhyang University Cheonan Hospital, Cheonan, Korea. ${ }^{2}$ Division of Rheumatology, Department of Internal Medicine, Soonchunhyang University College of Medicine, Cheonan, Chungchungnam-do, Korea. ${ }^{3}$ Division of Big Data and Management Engineering, Hoseo University, Asan, Korea.

\section{Received: 3 April 2019 Accepted: 21 August 2019}

Published online: 11 September 2019

\section{References}

1. Otter SJ, Lucas K, Springett K, Moore A, Davies K, Young A, et al. Comparison of foot pain and foot care among rheumatoid arthritis patients taking and not taking anti-TNF alpha therapy: an epidemiological study. Rheumatol Int. 2011;31(11):1515-9.

2. Ajeganova S, Andersson ML, Hafstrom I, Group BS. Association of obesity with worse disease severity in rheumatoid arthritis as well as with comorbidities: a long-term followup from disease onset. Arthritis Care Res (Hoboken). 2013;65(1):78-87.

3. Brenton-Rule A, Dalbeth N, Menz HB, Bassett S, Rome K. Foot and ankle characteristics associated with falls in adults with established rheumatoid arthritis: a cross-sectional study. BMC Musculoskelet Disord. 2016;17(1):22.

4. Aletaha D, Nell VP, Stamm T, Uffmann M, Pflugbeil S, Machold K, et al. Acute phase reactants add little to composite disease activity indices for rheumatoid arthritis: validation of a clinical activity score. Arthritis Res Ther. 2005;7(4):R796-806.

5. Prevoo ML, van 't Hof MA, Kuper $H H$, van Leeuwen MA, van de Putte LB, van Riel PL. Modified disease activity scores that include twenty-eight-joint counts. Development and validation in a prospective longitudinal study of patients with rheumatoid arthritis. Arthritis Rheum. 1995;38(1):44-8.

6. Smolen JS, Breedveld FC, Schiff MH, Kalden JR, Emery P, Eberl G, et al. A simplified disease activity index for rheumatoid arthritis for use in clinical practice. Rheumatology (Oxford). 2003;42(2):244-57.

7. Slama IB, Allali F, Lakhdar T, El Kabbaj S, Medrare L, Ngeuleu A, et al. Reliability and validity of CDAI and SDAI indices in comparison to DAS-28 index in Moroccan patients with rheumatoid arthritis. BMC Musculoskelet Disord. 2015;16:268.

8. Wechalekar MD, Lester S, Proudman SM, Cleland LG, Whittle SL, Rischmueller $M$, et al. Active foot synovitis in patients with rheumatoid arthritis: applying clinical criteria for disease activity and remission may result in underestimation of foot joint involvement. Arthritis Rheum. 2012; 64(5):1316-22

9. Naniwa T, Iwagaitsu S, Tamechika S, Maeda S, Niimi A. Signs of forefeet joint synovitis have a limited impact on patient's perception of rheumatoid arthritis disease activity and acute-phase reactants. Mod Rheumatol. 2016; 26(2):200-5.

10. Kapral T, Dernoschnig F, Machold KP, Stamm T, Schoels M, Smolen JS, et al. Remission by composite scores in rheumatoid arthritis: are ankles and feet important? Arthritis Res Ther. 2007;9(4):R72.

11. van Tuyl LH, Britsemmer K, Wells GA, Smolen JS, Zhang B, Funovits J, et al. Remission in early rheumatoid arthritis defined by 28 joint counts: limited consequences of residual disease activity in the forefeet on outcome. Ann Rheum Dis. 2012;71(1):33-7.

12. Jung SM, Kwok SK, Ju JH, Lee SW, Song JJ, Yoon CH, et al. Risk factors associated with inadequate control of disease activity in elderly patients with rheumatoid arthritis: results from a nationwide KOrean College of Rheumatology BIOlogics (KOBIO) registry. PLoS One. 2018;13(10):e0205651.

13. Felson DT, Smolen JS, Wells G, Zhang B, van Tuyl LH, Funovits J, et al. American College of Rheumatology/European league against rheumatism provisional definition of remission in rheumatoid arthritis for clinical trials. Ann Rheum Dis. 2011;70(3):404-13.

14. van der Leeden M, Steultjens MP, Ursum J, Dahmen R, Roorda LD, Schaardenburg DV, et al. Prevalence and course of forefoot impairments and walking disability in the first eight years of rheumatoid arthritis. Arthritis Rheum. 2008;59(11):1596-602.

15. Ranganath VK, Duffy EL, Garg VK, Woodworth T, Taylor M, Paulus HE, et al. Obesity impacts swelling of ankle and foot joints in early rheumatoid arthritis patients. J Clin Rheumatol. 2019;25(3):e8-e11.

16. Tanamas SK, Wluka AE, Berry P, Menz HB, Strauss BJ, Davies-Tuck M, et al. Relationship between obesity and foot pain and its association with fat mass, fat distribution, and muscle mass. Arthritis Care Res (Hoboken). 2012; 64(2):262-8.

17. Olaru L, Soong L, Dhillon S, Yacyshyn E. Coexistent rheumatoid arthritis and gout: a case series and review of the literature. Clin Rheumatol. 2017:36(12):2835-8

18. McWilliams DF, Marshall M, Jayakumar K, Doherty S, Doherty M, Zhang W, et al. Erosive and osteoarthritic structural progression in early rheumatoid arthritis. Rheumatology (Oxford). 2016;55(8):1477-88.

19. Bakker MF, Jacobs JW, Kruize AA, van der Veen MJ, van Booma-Frankfort C, Vreugdenhil SA, et al. Misclassification of disease activity when assessing individual patients with early rheumatoid arthritis using disease activity indices that do not include joints of feet. Ann Rheum Dis. 2012;71(6):830-5.

20. Studenic P, Smolen JS, Aletaha D. Near misses of ACR/EULAR criteria for remission: effects of patient global assessment in Boolean and index-based definitions. Ann Rheum Dis. 2012:71(10):1702-5.

21. van der Leeden M, Steultjens MP, van Schaardenburg D, Dekker J. Forefoot disease activity in rheumatoid arthritis patients in remission: results of a cohort study. Arthritis Res Ther. 2010;12(1):R3.

22. Inanc N, Yilmaz-Oner S, Can M, Sokka T, Direskeneli $H$. The role of depression, anxiety, fatigue, and fibromyalgia on the evaluation of the remission status in patients with rheumatoid arthritis. J Rheumatol. 2014; 41(9):1755-60.

23. Goossens J, Coustet B, Palazzo E, Dieude P, Ottaviani S. Overweight and obesity affect clinical assessment of synovitis in rheumatoid arthritis: comparison of ultrasonography and clinical exam. Clin Exp Rheumatol. 2019;37(1):49-54.

\section{Publisher's Note}

Springer Nature remains neutral with regard to jurisdictional claims in published maps and institutional affiliations.

Ready to submit your research? Choose BMC and benefit from:

- fast, convenient online submission

- thorough peer review by experienced researchers in your field

- rapid publication on acceptance

- support for research data, including large and complex data types

- gold Open Access which fosters wider collaboration and increased citations

- maximum visibility for your research: over $100 \mathrm{M}$ website views per year

At BMC, research is always in progress.

Learn more biomedcentral.com/submission 